Johnson \& Wales University ScholarsArchive@JWU

2008

\title{
The Effectiveness of Direct-Instruction and Student-Centered Teaching Methods on Students' Functional Understanding of Plagiarism
}

Richard J. Moniz Jr.

Johnson ఓWales University - Charlotte, richard.moniz@jwu.edu

Joyce Fine Ed. D.

Florida International University, finej@fiu.edu

Leonard Bliss PhD

blissl@fiu.edu

Follow this and additional works at: https://scholarsarchive.jwu.edu/staff_pub

\section{Repository Citation}

Moniz, Richard J. Jr.; Fine, Joyce Ed. D.; and Bliss, Leonard PhD, "The Effectiveness of Direct-Instruction and Student-Centered Teaching Methods on Students' Functional Understanding of Plagiarism" (2008). Library Staff Publications. 6.

https://scholarsarchive.jwu.edu/staff_pub/6 


\title{
The Effectiveness of Direct-Instruction and Student-Centered Teaching Methods on Students' Functional Understanding of Plagiarism
}

\author{
Richard Moniz \\ Joyce Fine \\ Leonard Bliss
}

\begin{abstract}
To improve students' functional understanding of plagiarism, a variety of approaches was tried within a comprehensive information literacy program. Sessions were taught as a "module" inside a required communications skills class at a private university. Approaches taken included control, direct-instruction, and student-centered sessions. Students were taught content and definitions regarding plagiarism, what circumstances or instances constitute plagiarism, where to go for help in avoiding plagiarism, and what constitutes appropriate paraphrasing. Pretest and posttest scores indicated that no approach performed significantly better than the others; however, even though students improved across all methods, they nonetheless showed the need for more hands-on practice.
\end{abstract}

KEYWORDS. Information literacy, plagiarism, academic dishonesty, teaching methods, constructivist, assessment

Richard Moniz, MA, MLIS, EdD, is Director of Library Services, Johnson \& Wales University, Charlotte, NC, 28202 (E-mail: richard.moniz@jwu.edu).

Joyce Fine, Ed. D., is Associate Professor, Florida International University, Miami, FL 33199 (E-mail: finej@fiu.edu).

Leonard Bliss, PhD, is Professor and Chair, Educational \& Psychological Studies, Florida International University, Miami, FL 33199 (E-mail: blissl@fiu.edu).

College \& Undergraduate Libraries, Vol. 15(3), 2008

Available online at http://cul.haworthpress.com

(0) 2008 by The Haworth Press. All rights reserved.

doi: $10.1080 / 10691310802258174$ 


\section{THE PROBLEM OF PLAGIARISM IN THE INTERNET ERA}

Although issues of academic dishonesty and plagiarism have been around for a very long time, they have never before been so publicly scrutinized. Simultaneously, the immediacy of access and the ability to "cut and paste" has led to concerns related to an apparent associated surge in plagiarism (Ashworth and Bannister 1997; McLafferty and Foust 2004; Norgaard, Arp, and Woodard 2003; Park 2003; Roig 1997; Sterngold 2004; Thomas 2004; Vernon, Bigna, and Smith 2001). And yet, little has been done to address the problem more actively by educating and preparing students better. The object of this study was to determine if a student-centered approach rather than traditional instruction would produce a better outcome for educating students with regard to plagiarism. While any attempt to educate students might be beneficial, we felt that a student-centered approach might better facilitate learning and comprehension.

Plagiarism can be dealt with both before and/or after the fact. Despite the changes that have taken place, most institutions seem focused on simply stating the penalties for academic dishonesty and plagiarism without fully explaining these concepts to students and insuring that they are adequately prepared to apply associated principles (Ercegovac and Richardson 2004). Furthermore, this approach relies on punishment, despite evidence that this is less than highly effective, hides flaws in conventional teaching methods, and may damage rapport with students (Drogemuller 1997; Lampert 2004; Lipson and Reindl 2003; McLafferty and Foust 2004; Sterngold 2004; Wilhoit 1994; Worthen 2004). It also seems to miss a fundamental point agreed upon in the literature that, whereas some instances are intentional, most plagiarism occurs because of a lack of understanding and knowledge (Gerdy 2004; Love and Simmons 1998; Vernon, Bigna, and Smith 2001; Roig).

\section{PLAGIARISM AND INFORMATION LITERACY}

In the broader context of information literacy (IL) the Association of College and Research Libraries (ACRL) has incorporated into its Information Literacy Competency Standards for Higher Education several components related to the issue of academic dishonesty and plagiarism. Furthermore, within the IL framework, a recent informal poll of information literacy specialists found issues of plagiarism and copyright to be among their top five concerns regarding IL (Arp and Woodard 2002). 
Thus, IL remains an illusive concept overall in its implementation; however, it generally calls for integrating a series of standards into appropriate places within a given institution's curriculum (Cunningham and Lanning 2002; Iannuzzi 1998; Johnston and Webber 2003). Although many definitions exist, one author has referred to the goal of IL as being the creation of lifelong learners (Breivik 2005), and others have stated, in similar fashion, "Information literacy is not a destination, it is an ongoing journey, and it is the key to lifelong learning" (Cunningham and Lanning, 343). The blueprint for higher education's integration of IL has been ACRL's Information Literacy Competency Standards for Higher Education. Of the five standards listed, it is Standard Five that addresses the ethical use of information. More specifically, with regard to performance indicators and outcomes, the following items most directly address issues of plagiarism and academic integrity:

Performance Indicator \#1: The information literate student understands many of the ethical, legal, and socio-economic issues surrounding information and information technology. Outcome d: Demonstrates an understanding of intellectual property, copyright, and fair use of copyrighted materials.

Performance Indicator \#2: The information literate student follows laws, regulations, institutional policies, and etiquette related to the access and use of information resources. Outcome f: Demonstrates an understanding of what constitutes plagiarism and does not represent work attributable to others as his/her own.

Performance Indicator \#3: The information literate student acknowledges the use of information sources in communicating the product or performance. Outcome a: Selects an appropriate documentation style and uses it consistently to cite sources. (ACRL 2000, p. 14)

One challenge with IL lies in creating a practical approach toward making the standards a part of the typical student's experience. Numerous recommendations exist for integrating IL throughout the curriculum, and, in fact, seem to outnumber other, more limited, approaches. 


\section{APPLYING INFORMATION LITERACY}

For smaller institutions the integration of these components remains a daunting challenge (Flaspohler 2003). From one of the author's personal experiences as a library director, many small academic and community college libraries have limited staff. With all of the other responsibilities (e.g., reference desk duties, collection development, cataloging, directing student employees, etc.) it remains to be seen how IL may be addressed. One solution might be to pick specific components and to address them in turn through specific classes with appropriate course objectives. Due to staff limitations, the core targeted classes should ideally be common to all students at a given institution. Over time, such an approach could deal with both plagiarism and other issues as well.

\section{A SOLUTION TO THE PROBLEM?}

For plagiarism instruction to be effective, it should be part of a broader IL program. Within this program, the most effective instructional approaches or treatments should be determined for conveying required content and skills. For students to be effective in avoiding plagiarism, they need to have the requisite skills such as knowledge of how to properly paraphrase and summarize text, how to provide appropriate documentation and citation when using sources, and what circumstances constitute the ethical and unethical application of information.

To facilitate student learning with regard to the issue of plagiarism, a variety of approaches, such as role-playing, group exercises, direct instruction, reading exercises, seat work, and classroom discussions, might be used. The need to determine the best way for students to learn the appropriate content and skills is imperative if educators are to adequately prepare information literate students for problems and challenges they will face upon graduation.

\section{USING TEACHING THEORY TO IMPROVE IL INSTRUCTION}

The necessity to incorporate IL and the further need to determine critical pieces on which to focus in a standardized way led to the discovery of a critical problem in the literature, a lack of understanding about how 
to avoid plagiarism, and, to a lesser extent, the ability to recognize all of the circumstances that formally constitute plagiarism. The next step in moving forward and beyond the current state was to determine the best approach toward addressing the problem. That is, what would be the best way to educate students more holistically (e.g., to affect their understanding, knowledge, and behaviors) while at the same time targeting the most critical area of application? One approach, based on Vygotsky's social constructivist theory, emphasizes the dialectical process that occurs between social environment and the individual as students attempt to make sense of knowledge and to apply it (Liu and Matthews 2005). For example, Sharkey and Culp (2005) emphasize an approach based on group work and active learning on the part of students. Brewer and Daane (2002) state that "social interaction is necessary for knowledge construction and active learning" (418). Concurrently, Lampert (2004) suggests an emphasis upon student-centered learning.

Other authors have described social constructivism, or student-centered instruction, in more specific ways. In practical terms, Cuban (2001) describes student-centered instruction as including equal or more talking on the part of students than teacher, students asking questions and engaging in discussion more than the teacher, the use of small groups, more flexibility for students in terms of movement around the classroom and the way that lessons are learned, and a more flexible use of work space. Conversely, Cuban describes the use of a teacher-centered approach as including significantly more talking by the teacher than by the students, instruction that involves the class as a whole as opposed to breakout groups, and traditional classroom seating arrangements with no real flexibility for students. In a practical sense, Burkhardt, MacDonald, and Rathemacher's (2003) IL workbook entitled Teaching Information Literacy: 35 Practical Standards-Based Exercises for College Students, which provides examples of suggested student-centered IL-based activities, is also helpful when exploring teaching theory alongside actual lesson plans.

Under other circumstances, perhaps those involving a more basic conveyance of knowledge, more traditional methods may be equally effective. For example, although Ismat Abdal-Haqq (1998) suggests constructivist approaches as a contributor to greater internalization of knowledge, he and others (e.g., Henry 2002) are careful to emphasize that other theoretical frameworks, such as direct instruction, may prove equally valid depending on instructional circumstances. Direct instruction is grounded in the teacher taking a formal, structured, and central role in instruction, breaking down 
larger lessons into smaller parts and employing frequent student feedback and practice (Rosenshine 1986).

\section{RESEARCH QUESTIONS}

A number of different approaches may be viable in preparing students to avoid plagiarism, but is one method more effective than another? On the basis of the foregoing rationale, the following research questions were the focus of this study:

Q.1: Will a student-centered (SC) approach based on dialecti$\mathrm{cal} /$ social constructivist-based instruction involving both group and role-playing exercises result in a better understanding of proper and improper paraphrasing (application) than direct teaching/traditional instruction (DI)?

Q.2: Will a SC approach based on dialectical/social constructivistbased instruction involving both group and role-playing exercises result in better understanding the contexts in which plagiarism occurs (theoretical understanding) than DI?

Q.3: Will the SC approach and DI approach result in a relatively equal improvement in content knowledge among students?

\section{HYPOTHESES}

$\mathrm{H}_{1}$ : Students receiving student-centered instruction will have higher mean scores on transfer/application of knowledge than students receiving PowerPoint presentations or direct instruction.

$\mathrm{H}_{2}$ : Students receiving student-centered instruction will have higher mean scores on their theoretical understanding than students receiving PowerPoint presentations or direct instruction.

$\mathrm{H}_{3}$ : Students receiving student-centered instruction, direct instruction, and PowerPoint presentations will have the same mean scores on content acquisition. 


\section{ACADEMIC DISHONESTY AND PLAGIARISM}

Any discussion of academic dishonesty and plagiarism in higher education must recognize the prolific work and writing of Donald McCabe, founder of the Center for Academic Integrity at Duke University. McCabe's work in turn, however, was initially based on that of a comprehensive multicampus study conducted by Bowers (1964) in 1963, which explored academic dishonesty among undergraduates. Bowers' landmark study was part of a broader examination of deviant behavior by students. According to Bowers, $75 \%$ of students surveyed admitted to some form of academic dishonesty with $30 \%$ admitting to plagiarism. Even more notable was the scope of Bowers' study that involved ninety-nine campuses of varied sizes and 5,000 students.

Following on the work of Bowers thirty years later, McCabe and Trevino (1997) conducted a similar study involving approximately 6,000 students (with 1,800 respondents) at thirty-one different institutions and came up with a self-reported cheating rate of $70 \%$, with $51 \%$ admitting to plagiarism-related behaviors. One general limitation with McCabe and Trevino's study, however, is that it was conducted at schools with more selective admissions policies. A pilot study conducted by one of the authors at the institution where this study took place, however, showed a self-reported rate of 52\% when asking 196 students whether or not they had included, verbatim, parts of other texts in their work without giving credit. Other studies corroborate the extent of this problem as well. For instance, Franklyn-Stokes and Newstead (1995), in a study that included the responses of 112 students, discovered a self-reported rate of plagiarismrelated behaviors (more specifically, paraphrasing without citing) of $66 \%$. Although all of these studies confirm the prevalence of the problem, Bowers' and McCabe and Trevino's studies carry special weight because of the large and diverse number of students involved. The most glaring problem with the abovementioned data is that it does not give any indication as to how effective a treatment might be. According to Lampert, most current research combines "plagiarism under the larger categorization of academic dishonesty" (348). She goes on to state "Unfortunately most recent attempts to integrate instruction on plagiarism have only scratched the surface. . . little has been written about information literacy in respect to the fifth ACRL information literacy standard on the ethical use of information" (349).

Other findings in the literature also led to the infusion of additional educational components into the actual instruction. For example, Davis and 
Luvigson (1995), in using a seven-item questionnaire administered to 2,153 undergraduates (juniors and seniors), discovered not only that $70 \%$ of the students admitted to cheating in high school and that approximately $50 \%$ of those who admitted to cheating admitted to doing it more than once but also that not allowing oneself enough time to get the work done was a significant factor in cheating. Oliphant (2002) also suggested management of one's time as a factor in addition to an inability to see the potential consequences if caught. As a result, time management and penalties are mentioned or explored very briefly in the instruction that this study employed.

Another key figure in plagiarism-related literature is Park. If Roig (whose work will be discussed shortly; 1997) and McCabe are the most important figures in the United States regarding academic dishonesty and plagiarism respectively, Park $(2003,2004)$ is a seminal figure in the United Kingdom with regard to academic dishonesty. Whereas numerous authors identify circumstances under which plagiarism occurs, Park has identified the most inclusive and coherent list. As a result, the instances of plagiarism he described were used to create the piece of the instrument in our study that seeks to determine whether students can or cannot identify theoretical examples of certain behaviors as representing plagiarism (e.g., Is it OK to borrow my friend's paper and turn it in as my own if he or she tells me it's OK with them?).

With regard to designing our instruction and assessment instrument, it is also important to note what some studies found not to be factors in the prevalence of student academic dishonesty. Among them is the inclusion of a stern statement about penalties for academic dishonesty. Paterson, Taylor, and Usick (2003), who conducted a qualitative study interviewing eight faculty and ten students, stated that this had no effect on whether students plagiarized. Likewise, Brown and Howell (2001), using 207 completed student surveys, concluded that the perceived seriousness of plagiarism was no different for students given a very severe "warning passage" at the beginning of an assignment and those who received no warning. Along these same lines, Braumoeller and Gaines (2001) also conducted a study involving approximately 180 students split between two separate political science courses at the University of Illinois at Urbana-Champagne. The experimental class received a severe warning about plagiarizing while the students serving as a control did not. They discovered that a warning "even in the strongest terms" had no effect (835).

Although McCabe and the other authors mentioned are critical sources in the literature regarding academic dishonesty (which includes plagiarism as a subset), Roig's work (1997) is the most prolific in specifically targeting 
plagiarism. His most significant contribution is an instrument that he calls the Plagiarism Knowledge Survey (PKS). Its original compilation consisted of ten restated versions of a given paragraph, of which eight constituted plagiarism. Later iterations included fewer items and different original text from which the samples were then changed as well. To ensure content validity, Roig consulted with two psychology instructors and two English instructors to help establish appropriate examples and agreement on which examples constituted plagiarism. When administered, respondents were required to identify which examples did and which did not constitute plagiarism. Roig first employed the PKS at two private colleges in New York with 316 student participants. He later conducted the study once again with an additional 231 undergraduates and came up with the same relative conclusion on both occasions:

The pattern of results obtained in the present study suggests that more than half of the students in our sample were not adequately informed about the proper procedures for paraphrasing text and thus could not correctly distinguish between various types of plagiarized versus correctly paraphrased text.... [T]he present findings suggest that plagiarism may be a larger problem than previously thought, and that $a$ substantial amount of this activity may stem from ignorance, on the part of students, over the proper rules for correctly paraphrasing text.... [M]ore attention needs to be paid to teaching students the proper skills to avoid plagiarism. (emphasis added, 118)

This conclusion highlights the false assumption that many educators make that students already know what does and does not constitute plagiarism specifically as it relates to proper paraphrasing.

After personally discussing the PKS with Roig (2004), we decided, based on the feedback that he shared, to alter the instrument and to incorporate it into the broader assessment instrument for this study. More specifically, Roig concurred that it would be appropriate to use a different, more basic text sample and to simplify the instructions. (Roig's versions were created for all ranges of respondents including graduate students and faculty whereas this study focuses exclusively on undergraduates.) Although most students could demonstrate a limited understanding of plagiarism in some way, a large number still had a problem when it came to application. While Roig did not actually test instructional approaches to see which worked best, he did identify a fundamental problem that seems to be relatively ignored. It is critical that students should not simply be 
told not to plagiarize; rather, they should receive detailed and in-depth instruction about what constitutes plagiarism in the hope that they might better understand and avoid this pitfall.

While giving Roig credit for pointing out specific challenges, it is also important to emphasize that this problem has since received attention from others as well. Ashworth, Bannister, and Thorne (1997), in interviews conducted with nineteen students, uncovered the fact that "In general, plagiarism is a less meaningful concept for students than it is for academic staff. .." (201). Auer and Krupar (2001), in their comprehensive discussion and literature review of the problem of "mouse click plagiarism," state that "some students do not know what plagiarism is or, if they know that it is wrong, they do not understand at what point using sources passes into plagiarism" (418). McGregor and Williamson (2005), in a qualitative study involving seventeen high school students, discovered that students who were very capable in defining plagiarism still had problems in understanding its application.

One other substantial study that did go beyond just stating or discussing the problem was also based on the use of Roig's PKS. Landau, Druen, and Arcuri (2002) conducted a study with ninety-four undergraduates at York College who took the PKS and then were required to restate information from a paragraph without plagiarizing. Students in the experimental group who received feedback in between taking the PKS and making the attempt (in the form of a PowerPoint presentation that went over the correct answers) did significantly better than those who received no feedback at all, thus demonstrating that even minimal instruction could have a positive effect.

\section{PILOT STUDY}

Before the study under discussion, one of the authors conducted two pilot studies over the course of the 2004-2005 and 2005-2006 academic years. The original pilot, which employed a basic pretest and posttest approach, included only two classes with a total of approximately sixty undergraduates whereas the second pilot involved 196 undergraduates. The primary purpose of those studies was to determine whether the studentcentered approach was practical as well as whether it and the instrument used to collect data needed reworking. Based on feedback from library staff and the course instructors, changes were made to include more detail for the students who would participate in a role-playing exercise. It was 
also determined that the examples used in a group exercise needed to be shortened and that the tests used to collect data needed to have simpler instructions.

\section{STUDY PARTICIPANTS}

The participants in the present study were all undergraduate students attending Johnson \& Wales University, Charlotte Campus. This institution's focus is educating career-oriented students. During the 2005-2006 academic year, when this study took place, the Charlotte campus initially enrolled approximately two thousand students. Of that number, 289 participated in this study, with all of the students enrolled in the Communications Skills course during the spring semester. Two hundred of these students were present for both the pretest and posttest, and these students constituted the sample of participants of the study. These participants were demographically distributed as follows. In terms of program areas, eighty-eight students identified themselves as culinary arts majors, fifty-four as hospitality majors, and fifty-seven as business majors. Eighty of the students were men and 120 were women. One hundred thirty-four students were between seventeen and nineteen years of age, fifty-two students were between twenty and twenty-two years old, and fourteen were twenty-three years or older. The average grade point average (GPA) was 3.12 out of a possible 4.0.

\section{INSTRUCTIONAL APPROACHES}

While identical content was applied in all circumstances, three different instructional approaches were used. Each of these instructional approaches is described below.

\section{Direct Instruction}

The direct-instruction (DI) method included lecture, board-based instruction, seat work, and occasional student feedback. The DI sessions began with the librarian working with the class as a whole to define plagiarism and related terms on the board. The librarian then placed examples of text on the board and engaged the class in a discussion of why (or why not, as the case may be) a particular manipulation of that text would be considered plagiarism. Following this, the librarian placed another example on 
the board and students were given time to attempt a proper paraphrasing independently. Individual participants were then asked to share their examples, and the librarian asked the other participants whether the example was acceptable and to justify their judgments. The session continued as the librarian led students in identifying how students plagiarize, how teachers uncover plagiarism, what penalties for plagiarism exist at their institution, and strategies for avoiding plagiarism. For example, topics such as better note taking, time management, and use of the Writing Center were explored. All major points were written on the board.

\section{PowerPoint Lecture}

Another didactic approach (which served as the control group) was the PowerPoint (PPT) lecture. This approach, while including limited opportunity for student-teacher interaction, was much more straightforward and didactic than the DI sessions. It differed most substantially in the sense that, rather than working more with students to define relevant words, the terms, such as a definition of plagiarism, were simply provided on PowerPoint slides. Additionally, the librarian did not manipulate the text, but rather had several unacceptable and one acceptable paraphrase attempt already written into the slides. The other material mentioned in the description of DI was delivered in a similar fashion using PowerPoint slides. No seatwork was conducted in this teaching strategy.

\section{Student-Centered Approach}

The student-centered (SC) approach included group and role-playing exercises. Although the instructor played a significant role, it was primarily to provide guidance, to answer questions, and to help students uncover information that they might have left out of their discussions and role plays. These sessions began with the librarian handing out a group exercise that required students, in groups of three to five, to develop definitions for plagiarism and plagiarism-related terms. While in their groups, they examined and discussed various paraphrasing examples to determine which would or would not be considered plagiarism. After a period of time, the librarian asked the groups to share their conclusions with the class. The librarian's role was to moderate any disagreement between groups by fostering further discussion.

The second part of the SC approach involved role-playing exercises, two of which highlighted plagiarism and one copyright violation. Student volunteers were given time to discuss their parts with one another and to 
go over a list of points they would be expected to make. For example, one student might be called upon to play an "instructor" who must confront a "student" who has plagiarized. In the plagiarism examples, the "instructor" would be required to tell "students" how they discovered the plagiarism, why what "students" did is considered plagiarism, the possible penalties students who plagiarize can incur, and strategies that can be used to avoid plagiarizing in the future. The "student," on the other hand, would be required to offer typical excuses for plagiarizing, such as having two jobs, waiting until the last minute, having confusion about citations, and so on. It should be noted that the students were given wide latitude and encouraged to be creative in their roles.

\section{INSTRUMENTATION}

The instrument used to collect data in this study combines components of several instruments into one so as to get a more complete picture of the factors being studied. The complete instrument, in addition to soliciting demographic information such as major, GPA, gender, and age, tested the following areas: transfer and application of knowledge about plagiarism, theoretical instances and understanding of plagiarism, and content knowledge about terms used in discussing plagiarism.

\section{Transfer and Application of Knowledge of Plagiarism}

The instrument used in this study was compiled by the authors and incorporated an adapted version of the Plagiarism Knowledge Survey (PKS) initially developed by Roig (1997). In this part, students are asked to determine which of the examples are successfully paraphrased and which would constitute plagiarism.

Before this study was undertaken, Roig was contacted in 2004 to discuss our use of his instrument and possible adaptations to the specific group being studied. As a result of this communication and the two pilot studies, the examples and instructions were simplified to make them more relevant and easier to understand by a typical Johnson \& Wales undergraduate. Since the PKS provides six examples in this area, a total score of six on this portion of the instrument indicates that the student has correctly judged each example. 


\section{Theoretical Understanding of Plagiarism}

Another aspect of the study was to determine whether students understand what circumstances (besides improper paraphrasing) constitute plagiarism. This involves the area described as theoretical instances and understanding. Within this section of the instrument, students were asked to identify which actions, such as copying a paper from the Internet, copying a paper from a friend, or including another author's ideas without citation, and so on are examples of plagiarism. In total, six examples were provided. In these examples one consisted of an acceptable use of another author's ideas and the other five represented various instances of plagiarism. As in the section of the instrument measuring transfer and application of knowledge of plagiarism, a score of six in this section also indicated that a student judged each instance correctly.

\section{Content}

Yet another section of the instrument included content-based multiple choice questions, which, for example, asked students to select from alternative definitions provided for terms such as plagiarism, paraphrasing, and copyright. A score of ten indicated that a student selected the correct response for all items in this area.

\section{Fidelity of Treatments}

A final feature of the posttest was a series of questions asking students to indicate their levels of agreement concerning the presence of particular activities that might have been included in their instructional experiences about plagiarism. This was done to provide evidence as to whether the librarian or instructor conducted the treatments as they were intended. These data were collected using a series of six Likert scales that asked the participants to indicate their levels of agreement with statements that a particular activity had occurred during instruction.

\section{PROCEDURE}

Classes were taken intact and randomly assigned to instructional approaches. Librarians were randomly assigned to two of four classes receiving each treatment. In other words, the sample included two DI, two 
SC, and two PPT sessions for each of two librarians, for a total of twelve classes.

Instruction was conducted within a time frame slightly greater than one hour in an English Communications Skills course. This course is a requirement for all four-year students. English faculty scheduled to teach the course were contacted before the spring semester began and asked if the librarians could provide the instruction between the second and fourth week of class. All of these faculty members agreed to allow the librarians to do so. They were all also asked not to address any issues of plagiarism before the librarian's visit to their class.

All classes received the pretest version of the instrument followed by one of the instructional approaches. Following the pretest and the administration of instruction, the librarian returned to the class approximately two weeks later to administer the posttest. After this was done, pretest and posttest data were matched based on student-provided J numbers (unique numbers assigned to each student).

\section{DATA ANALYSIS}

Since whole classes were assigned to the three educational treatments, it is possible that the groups were different on variables that could affect their learning about plagiarism. For instance, it could be that older students reacted better to direct instruction than younger students, but younger students reacted better than older students to PowerPoint instruction. In such a case we could not know whether any differences observed between participants' performance after the educational treatments were due to the treatments themselves or just to the differences between groups due to the differences of characteristics of the participants prior to the treatments. Thus, the treatment groups were compared on (a) academic major, (b) age, (c) gender, and (d) grade point average (GPA). Since the librarian/instructors were assigned to the treatment classes randomly, it was also important to eliminate the instructor effect on the groups as a possible cause of group differences after treatment. To do this, the data was examined to determine if the proportion of participants taught by each librarian/instructor was the same in each of the three treatments. Chi-squared tests were used to examine all of the variables listed above except GPA. The GPAs of the participants in the three groups were compared using analysis of variance. 
To test the hypotheses involving participants' agreement with the statements about activities used in instruction, one-way analysis of variance was used to determine if there were any differences in agreement between those who received each of the three educational treatments. The primary purpose of this analysis was to make sure that instruction in each of the three treatment groups covered the same material so that we could be confident that any differences seen between the groups in their knowledge of plagiarism were due to the teaching method used and not due to the content presented in the course.

Finally, analyses of variance (ANOVAs) were conducted to test the main hypotheses about the relative efficacy of the three educational treatments. Three ANOVAs were carried out (one for each of the three sections of the instrument) with the pretreatment scores used to equate the treatment groups. Specifically, these statistical tests were used to determine if there were any differences in participant learning due to the educational treatments used by the library instructors.

\section{EQUIVALENCE OF GROUPS}

Table 1 presents the results of the statistical tests designed to examine the equivalency of the three treatment groups on the demographic characteristics listed above and in the distribution of the instructors among the three educational treatments.

The results of the comparisons showed that there were equal proportions of participants in each treatment group based on their ages and gender. In addition, proportions of participants who received instruction from each of the librarians were the same across treatment groups.

There were significant differences in participants' majors across treatments. For example, more Culinary Arts students attended the PowerPoint and student-centered instruction than direct instruction. In addition, more business majors were in the direct-instruction classes than in the PowerPoint or student-centered instruction.

An analysis of variance indicated that the GPAs differed among the treatment groups. The average of the GPAs obtained before treatments was higher for the student-centered instruction treatment $(M=3.36)$ than for participants in the PowerPoint instruction $(M=3.04)$ or direct instruction $(M=3.12)$. Despite the existence of this difference, we decided that the small size of the difference made it unnecessary to account for this difference in further analysis. 
TABLE 1. Participant Demographics Data By Instructional Approach

\begin{tabular}{|c|c|c|c|c|c|c|}
\hline Demographic & $\begin{array}{l}\text { Power Point } \\
\text { Instruction } \\
n(\%)\end{array}$ & $\begin{array}{l}\text { Direct- } \\
\text { Instruction } \\
n(\%)\end{array}$ & $\begin{array}{l}\text { Student-Centered } \\
\text { Instruction } \\
n(\%)\end{array}$ & $x^{2}$ & $d f$ & $p$ \\
\hline Program & & & & 12.33 & 4 & $0.02^{*}$ \\
\hline Culinary Arts & $40(45.5)$ & $17(19.3)$ & $31(35.2)$ & & & \\
\hline Hospitality & $21(26.6)$ & $20(31.7)$ & $13(22.8)$ & & & \\
\hline Business & $18(22.8)$ & $26(41.3)$ & $13(22.8)$ & & & \\
\hline Age & & & & 2.51 & 4 & 0.64 \\
\hline $17-19$ & $49(62.0)$ & 46 (71.9) & $39(68.4)$ & & & \\
\hline 20-22 & 25 (31.6) & $14(21.9)$ & $13(22.8)$ & & & \\
\hline $23+$ & $5(6.3)$ & $4(6.3)$ & $5(8.8)$ & & & \\
\hline Gender & & & & 1.21 & 2 & 0.55 \\
\hline Male & $35(44.3)$ & $25(39.1)$ & $20(35.1)$ & & & \\
\hline Female & $44(55.7)$ & 39 (60.9) & 37 (64.9) & & & \\
\hline Librarian & & & & 0.18 & 2 & 0.92 \\
\hline Librarian \#1 & $37(46.8)$ & $28(43.8)$ & $25(43.9)$ & & & \\
\hline Librarian \#2 & 42 (53.2) & $36(56.3)$ & $32(56.1)$ & & & \\
\hline
\end{tabular}

Note: ${ }^{*} p<.05$

\section{INDUCTION OF TREATMENTS}

To determine the internal validity of the implementation of the three treatments, the study compared the students' perceptions of the treatment in which they participated by treatment group. This would be a measure of how faithfully and efficaciously the librarian/instructors carried out the treatments.

As noted in the Methods section, we obtained a measure of the posttreatment student perceptions of the treatment strategies used by librarians and instructors during the training sessions. Specifically, students were asked their levels of agreement with statements that their sessions involved interaction, seatwork, lecturing, and group work. Low scores indicated participant agreement that a particular activity took place whereas high scores indicated disagreement. The following statements constituted this portion of the instrument:

Statement \#1 - The session was highly interactive.

Statement \#2 - Principles describing plagiarism were taught. 
Statement \#3 - The session involved mostly lecture.

Statement \#4 - Seatwork exercises were used to teach about plagiarism.

Statement \#5 - Blatant and unintentional plagiarism cases were discussed and compared.

Statement \#6 - Students worked in groups to define plagiarism and to identify examples.

As hoped for, differences were not significant with items such as "Principles of plagiarism were taught." There were, however, expected differences when students responded to statements such as "The session was highly interactive." This confirmed the authors' claim that the experimental sessions were viewed as student centered from the students' perspective as well as their own. The data from this portion of the instrument are summarized in Table 2.

TABLE 2. Pererception of Teaching Method by Instructional Approach

\begin{tabular}{|c|c|c|c|c|c|c|c|c|c|}
\hline \multirow[b]{2}{*}{ Statement } & \multicolumn{2}{|c|}{$\begin{array}{l}\text { PowerPoint } \\
\text { Instruction }\end{array}$} & \multicolumn{2}{|c|}{$\begin{array}{l}\text { Direct- } \\
\text { Instruction }\end{array}$} & \multicolumn{2}{|c|}{$\begin{array}{l}\text { Student- } \\
\text { Instruction }\end{array}$} & \multirow[b]{2}{*}{$F$} & \multirow[b]{2}{*}{$d f$} & \multirow[b]{2}{*}{$p$} \\
\hline & $M$ & $S D$ & $M$ & $S D$ & $M$ & $S D$ & & & \\
\hline $\begin{array}{l}\text { The session was highly } \\
\text { interactive }\end{array}$ & 2.61 & 0.95 & 2.63 & 1.13 & 2.04 & 0.80 & 7.21 & 2,197 & $<.01^{*}$ \\
\hline $\begin{array}{l}\text { Principles describing } \\
\text { plagiarism were } \\
\text { taught }\end{array}$ & 1.68 & 1.01 & 1.88 & 1.30 & 1.61 & 0.80 & 1.01 & 2,197 & .37 \\
\hline $\begin{array}{l}\text { The session involved } \\
\text { mostly lecturing }\end{array}$ & 2.30 & 1.04 & 2.38 & 1.06 & 3.09 & 0.89 & 11.43 & 2,197 & $<.01^{*}$ \\
\hline $\begin{array}{l}\text { Seatwork exercises } \\
\text { were used to teach } \\
\text { about plagiarism }\end{array}$ & 2.24 & 1.11 & 2.28 & 1.27 & 1.82 & 0.76 & 3.55 & 2,197 & $.03 *$ \\
\hline $\begin{array}{l}\text { Blatant and } \\
\text { unintentional } \\
\text { plagiarism cases } \\
\text { were discussed }\end{array}$ & 1.84 & 1.06 & 2.02 & 1.24 & 1.74 & 0.84 & 1.09 & 2,197 & .34 \\
\hline $\begin{array}{l}\text { Students worked in } \\
\text { groups to define } \\
\text { plagiarism and } \\
\text { discuss examples }\end{array}$ & 3.78 & 1.23 & 3.38 & 1.35 & 1.58 & 0.94 & 60.45 & 2,197 & $<.01^{*}$ \\
\hline
\end{tabular}

Note: ${ }^{*} p<.05$ 


\section{TESTS OF THE RESEARCH HYPOTHESES}

The internal consistency reliability of the posttest scores on three scales of the data collection instrument was examined using Cronbach's alpha reliability coefficient. For the Theoretical Understandings, Transfer/Applications, and Content scores, the values of alpha were $.65, .49$, and .44 , respectively. The particularly low values for the scores on the latter two sections are noteworthy but not particularly unexpected since each section of the instrument contained a rather limited number of items. For this reason and because this study is a preliminary investigation of the effects of instruction in this area, these values are considered acceptable.

After accounting for potential initial differences in groups, the appropriate delivery of treatments, and the reliability of the instrument sections, three analyses of variance were conducted to test the main research hypotheses. Three $2 \mathrm{X}$ (2) mixed ANOVAs were conducted separately of each dependent variable (i.e., the separate scores measuring plagiarism). In each analysis, the within-Ss independent variable was time of measurement (pre- or posttreatment) and the between-Ss variable was the method of instruction.

Hypothesis \#1 - Students receiving student-centered instruction will have higher mean scores on transfer/application than students receiving PowerPoint presentations or direct instruction.

This hypothesis would be supported by the observation of a significant interaction between the change of scores on the pre- and posttreatment transfer/application measures and the method of instruction used, followed by post hoc tests showing that the change was highest for students receiving student-centered instruction. Put simply, we expected that there would be a difference between the pre- and posttreatment scores since instruction was going on in all groups. The research question actually asked whether the change in these scores over the time in treatment was different between any of the pairs of the three groups. If it were, there would be an interaction between the time of instruction (i.e., pre- and posttreatment) and the educational treatment used. The analyses of variance would tell us whether we had such an interaction. We could then conduct so-called post hoc tests to determine which pairs of treatment measures were different from each other. No interactions were identified between the differences in transfer/application measures over the course of treatment and the instructional method. Thus, the hypothesis that student-centered instruction 
was superior to the other two methods of instruction in teaching transfer and application of knowledge of avoiding plagiarism was not supported.

Hypothesis \#2 - Students receiving student-centered instruction will have higher mean scores on theoretical understanding than students receiving PowerPoint presentations or direct instruction.

Again, we conjectured that Hypothesis \#2 would be supported by the observation of a significant interaction between the change of scores on the pre- and posttreatment theoretical understanding measures and the method of instruction used, followed by post hoc tests showing that the change was highest for students receiving student-centered instruction. However, no interactions were found between the differences in theoretical knowledge and the instructional method. Therefore, all groups made gains on the theoretical knowledge but none of the groups was superior to the other in meeting this objective.

Hypothesis \#3 - Students receiving student-centered instruction, direct instruction, and PowerPoint presentations will have the same mean scores on content acquisition.

Unlike the other two hypotheses, this hypothesis suggests that no differences would exist between treatments in terms of their ability to facilitate the learning outcomes that were desired (a null hypothesis). We found no evidence that differences across groups were present.

\section{DISCUSSION OF RESULTS}

\section{Research Question \#1}

The first research question considered whether SC instruction integrated within an IL program could significantly improve student functional understanding of plagiarism specifically with regard to transfer and application. We determined that the SC approach did not offer any specific advantages over the other different instructional approaches. In fact, this approach performed just as well as DI and PPT in helping students understand and identify properly paraphrased material better. There are many reasons why this may be the case. As Roig (1997) has indicated, students generally struggle with the concept of plagiarism when it comes to 
application. Students in our study really did seem to struggle especially when they were asked to actively paraphrase material on their own and when attempting to recognize paraphrased examples. With regard to fidelity of treatment, it may be that a one-time session is not sufficient for demonstrating the worth of one approach over another. That is to say, if additional group, role playing, and other student-centered activities were employed over a longer period of time (perhaps several class sessions), a different outcome is possible. Other authors have pointed out the connection between treatment effectiveness and time spent on task (Greenwood and Finney 1993). One of the major challenges, however, is that students already have numerous other curricular components consuming their time. To include more sessions on plagiarism might weaken other critical areas.

\section{Research Question \#2}

A second research question was whether the SC approach would be better than the DI approach in improving student theoretical understanding of what types of instances or circumstances constitute plagiarism. While improvements did occur, again, no significant difference was found between the two approaches. With regard to theoretical understanding it became clear to us over time that this area is more strictly factual (as opposed to skill-based). It is likely that students simply learned what they could from each approach. In other words, while the first research question required students to build certain skills (e.g., paraphrasing, providing citation, etc.) the second requires more simply that students have a basic understanding (e.g., if you do x you have plagiarized). Because the latter approach does not necessarily require practice to the extent of the former it is possible that students might benefit from simply being told this information.

\section{Research Question \#3}

The third and final research question was whether the improved recollection of content knowledge would be different between the SC and DI groups. It was not. Perhaps most interestingly, however, none of the groups exhibited any demonstrable difference in understanding as a result of the various instructional methods used, by both method and time of test. The literature supported the view that students have a basic understanding and can readily define plagiarism; however, students possess a limited understanding when it comes to application. Still, we were surprised 
to discover that the different methods had no significant positive impact at all.

\section{Secondary Findings}

One of the most important findings of this research was that a main effect was realized with regard to time of test concerning transfer/application and theoretical understanding. As in the study by Flaspohler (2003), we discovered that students could benefit from modular instruction (despite its time limitations as mentioned above). Unlike previous studies by Bowers (1964), McCabe and Trevino (1997), and Cummings, Maddux, Harlow, and Dyas (2002), which simply sought to determine the extent of the problem and which subsumed plagiarism within the very broad umbrella of academic dishonesty, this study showed that an impact can be made on student capabilities and that it can be done in a targeted fashion. Perhaps more significantly, other authors such as Ashworth and Bannister (1997), Auer and Krupar (2001), and McGregor and Williamson (2005) have all already gone further by illustrating the kind of general confusion that exists among undergraduates (particularly with regard to proper paraphrasing and citation). Like the study by Landau, Druen, and Arcuri (2002), which shows that students can improve their skills when given constructive feedback, this study shows that instruction of almost any kind improves skills in this area of very obvious deficiency.

\section{IMPLICATIONS FOR FURTHER RESEARCH}

Future research in the area of improving students' functional understanding of plagiarism is necessary. One implication of this study is that more time should be spent proactively assisting students to learn what constitutes proper and improper paraphrasing. Future studies might take a more qualitative approach, such as requiring students to paraphrase multiple examples in a variety of contexts (i.e., as a class, in groups, as seat work, as homework), grading those examples, and then providing immediate feedback. Another approach might be to incorporate a variety of features from the three approaches used in this study into a blended approach directed toward teaching the same subject matter. Providing some of the more basic information as a handout and focusing on the more difficult concepts and problems when the students are in front of the instructor might be a better use of time and could also produce different results. 


\section{CONCLUSION}

In closing, the level of interactivity with which students were taught practical skills regarding the avoidance of plagiarism was not significant within the short time frame in which the treatment was applied. Perhaps of greater significance, the fact that all treatments resulted in significant gains indicates a definite need to provide undergraduates with a better understanding of plagiarism as opposed to simply relying upon vague admonishments to avoid it at all costs.

\section{REFERENCES}

Abdal-Haqq, I. 1998. Constructivism in teacher education: Considerations for those who would link practice to theory (Report No: EDO-SP-97-8). Washington, DC: Office of Educational Research and Improvement (ERIC Document Reproduction Service No. ED426986).

Arp, L., and B. S. Woodard. 2002. Recent trends in information literacy and instruction. Reference \& User Services Quarterly 42:124-132.

Ashworth, P., and P. Bannister. 1997. Guilty in whose eyes? University students' perceptions of cheating and plagiarism in academic mark and assessments. Studies in Higher Education 22:187-203.

Ashworth, P., P. Bannister, and P. Thorne. 1997. Guilty in whose eyes? University students' perceptions of cheating and plagiarism in academic work and assessments. Studies in Higher Education 22:187-203.

Association of College \& Research Libraries. 2000. Information literacy competency standards for higher education. http://www.ala.org/ala/acrl/acrlstandards/ informationliteracycompetency.htm.

Auer, N. J., and E. M. Krupar. 2001. Mouse click plagiarism: The role of technology in plagiarism and the librarian's role in combating it. Library Trends 49:415-433.

Bowers, W. J. 1964. Student dishonesty and its control in college. New York: Bureau of Applied Research, Columbia University.

Braumoeller, B. F., and B. J. Gaines. 2001. Actions do speak louder than words: Deterring plagiarism with the use of plagiarism-detection software. PS: Political Science and Politics: 34:835-839.

Breivik, P. S. 2005. 21st century learning and information literacy. Change 37:20-27.

Brewer, J., and C. J. Daane. 2002. Translating constructivist theory into practice in primarygrade mathematics. Education 123:416-422.

Brown, V. J., and M. E. Howell. 2001. The efficacy of policy statements on plagiarism: Do they change student views? Research in Higher Education 42:103-118.

Burkhardt, J. M., M. C. MacDonald., and A. J. Rathemacher. 2003. Teaching information literacy: 35 practical standards-based exercises for college students. Chicago: American Library Association. 
Cuban, L. 2001. How did teachers teach, 1890-1980. Theory Into Practice 22:159-165.

Cummings, R., C. D. Maddux., S. Harlow., and L. Dyas. 2002. Academic misconduct in undergraduate teacher education students and its relationship to their principled moral reasoning. Journal of Instructional Psychology 29:286-296.

Cunningham, T., and S. Lanning. 2002. New frontier trail guides: Faculty-librarian collaboration on information literacy. Reference Services Review 30:343-348.

Davis, S., and H. W. Luvigson. 1995. Additional data on academic dishonesty and a proposal for remediation. Teaching of Psychology 22:119-121.

Drogemuller, R. 1997. Designing cyber-assignments. Australian Science Teachers Journal 43:42-44.

Ercegovac, Z., and J. Richardson. 2004. Academic dishonesty, plagiarism included, in the digital age: A literature review. College \& Research Libraries 65:301-318.

Flaspohler, M. R. 2003. Information literacy program assessment: One small college takes the big plunge. Reference Services Review 31:129-140.

Franklyn-Stokes, A., and S. E. Newstead. 1995. Undergraduate cheating: Who does what and why? Studies in Higher Education 20:159-172.

Gerdy, K. 2004. Law student plagiarism: Why it happens, where it's found, and how to find it. Brigham Young University Education \& Law Journal 4:431-440.

Greenwood, C. R., and R. Finney, R. 1993. Monitoring, improving, and maintaining quality implementation of classwide peer tutoring. Education \& Treatment of Children 16:19-29.

Henry, M. 2002. Constructivism in the college classroom. The History Teacher 36:65-74.

Iannuzzi, P. 1998. Faculty development and information literacy: Establishing campus partnerships. Reference Services Review 26:97-102.

Johnston, B., and S. Webber. 2003. Information literacy in higher education: A review and case study. Studies in Higher Education 28:335-352.

Lampert, L. D. 2004. Integrating discipline-based anti-plagiarism instruction into the information literacy curriculum. Reference Services Review 32:347-355.

Landau, J. D., P. B. Druen., and J. A. Arcuri. 2002. Methods for helping students avoid plagiarism. Teaching of Psychology 29:112-115.

Lipson, A., and S. M. Reindl. 2003. The responsible plagiarist. About Campus 8:7-14.

Liu, C. H., and R. Matthews. 2005. Vygotsky's philosophy: Constructivism and its critics examined. International Education Journal 6:386-399.

Love, P. G., and J. Simmons. 1998. Factors influencing cheating and plagiarism among graduate students in a college of education. College Student Journal 32:539-551.

McCabe, D. L., and L. K. Trevino. 1997. Individual and contextual influences on academic dishonesty. Research in Higher Education 38:379-396.

McGregor, J. H., and K. Williamson. 2005. Appropriate use of information at the secondary school level: Understanding and avoiding plagiarism. Library \& Information Science Research 27:496-512.

McLafferty, C. L., and K. M. Foust. 2004. Electronic plagiarism as a college instructor's nightmare-Prevention and detection. Journal of Education for Business 79:186-189.

Norgaard, R., L. Arp., and B. S. Woodard. 2003. Writing information literacy in the classroom. Reference \& User Services Quarterly 43:220-226.

Oliphant, T. 2002. Cyber-plagiarism: Plagiarism in a digital world. Feliciter 48:78-80. 
Park, C. 2003. In other (people's) words: Plagiarism by university students - literature and lessons. Assessment \& Evaluation in Higher Education 28:471-488.

Park, C. 2004. Rebels without a clause: Towards an institutional framework for dealing with plagiarism by students. Journal of Further and Higher Education 28:291-306.

Paterson, B., L. Taylor., and B. Usick. 2003. The construction of plagiarism in a college of nursing. Learning in Health and Social Care 2:147-158.

Roig, M. 1997. Can undergraduate students determine whether text has been plagiarized? Psychological Record 47:113-123.

Rosenshine, B. V. 1986. Synthesis of research on explicit teaching. Educational Leadership 43:60-69.

Sharkey, J. R., and F. B. Culp. 2005. Cyberplagiarism and the library: Issues and solutions. The Reference Librarian 44:103-116.

Sterngold, A. 2004. Confronting plagiarism. Change 36:16-21.

Thomas, D. A. 2004. How educators can more effectively understand and combat the plagiarism epidemic. Brigham Young University Education \& Law Journal 2:421-430.

Vernon, R. F., S. Bigna., and M. L. Smith. 2001. Plagiarism and the web. Journal of Social Work Education 37:193-196.

Wilhoit, S. 1994. Helping students avoid plagiarism. College Teaching 42:161-164.

Worthen, K. J. 2004. Discipline: An academic dean's perspective on dealing with plagiarism. Brigham Young University Education \& Law Journal 2:441-448.

Received: 09/12/07

Revised/Reviewed: 01/19/08

Accepted: 02/12/08 